\title{
CONSERVAÇÃO DE INFLORESCÊNCIAS DE HELICÔNIAS PREVIAMENTE ADUBADAS COM DOSES CRESCENTES DE NITROGÊNIO E POTÁSSIO ${ }^{1}$
}

\author{
GENILDA CANUTO AMARAL ${ }^{2 *}$, MÁRKILLA ZUNETE BECKMANN-CAVALCANTE ${ }^{3}$, LEONARDO PEREIRA DA \\ SILVA BRITO $^{4}$, MARLUCE PEREIRA DAMASCENO LIMA ${ }^{4}$, JOSY ANTEVELI OSAJIMA $^{5}$
}

\begin{abstract}
RESUMO - A longevidade das hastes florais é um dos principais aspectos observados na produção de flores para corte, constituindo-se um pré-requisito para a qualidade do produto e sucesso da comercialização. Nesse sentido, objetivou-se avaliar a conservação de inflorescências de helicônias com ou sem renovação da água de manutenção, previamente adubadas com doses crescentes de nitrogênio e potássio. Foram utilizadas inflorescências de helicônias da espécie Heliconia psittacorum $x$ H. spathocircinata cv. Golden Torch cultivadas a céu aberto no Setor de Floricultura da UFPI, Bom Jesus (PI), sob doses crescentes de adubação com N e K. O delineamento foi em blocos casualizados em esquema fatorial $4 \times 4 \times 2$, correspondendo a: i) doses de $\mathrm{N}(0,120$, 180 e $240 \mathrm{~g}$ de $\left.\mathrm{N} \mathrm{cova}^{1}\right)$; ii) doses de $\mathrm{K}\left(0,120,180\right.$ e $240 \mathrm{~g}$ de $\mathrm{K}_{2} \mathrm{O}$ cova $\left.^{-1}\right)$; e iii) renovação da água de manutenção (sem e com renovação) com três repetições e três hastes cada uma. Fora realizado a avaliação de absorção de água pelas hastes florais, perda de massa fresca das hastes florais, massa seca das hastes florais e longevidade pós-colheita. A dose de $180 \mathrm{~g}$ cova $^{-1}$ tanto de $\mathrm{N}$ quanto $\mathrm{K}$ proporcionou a maior longevidade das hastes florais com manutenção da qualidade. A absorção de água pelas hastes florais e sua massa seca após a colheita foram influenciadas pela adubação prévia de $\mathrm{N}$ e K. A renovação da água de manutenção também influenciou positivamente na longevidade das hastes florais, sendo um manejo indicado para manter a qualidade póscolheita.
\end{abstract}

Palavras-chave: Heliconia psittacorum. Qualidade pós-colheita. Solução de manutenção.

\section{CONSERVATION OF HELICONIA INFLORESCENCES PREVIOUSLY FERTILIZED WITH IN- CREASING DOSES OF NITROGEN AND POTASSIUM}

\begin{abstract}
The post-harvest of floral stems is one of the main features observed in the production of flowers for cutting, becoming a prerequisite for product quality and successful marketing. In this sense, the objective was to evaluate the conservation of heliconias inflorescences with or without renewal of the water maintenance, previously fertilized with increasing doses of nitrogen and potassium. Inflorescences of Heliconia psittacorum $x$ H. spathocircinata cultivar Golden Torch were used and grown in open conditions in the Floriculture area at UFPI, city of Bom Jesus, Piauí State under increasing doses of fertilization with N and K. The stems were harvested in the morning, standardized and placed in containers with $500 \mathrm{~mL}$ of water. The design was a randomized block in factorial $4 \times 4 \times 2$, corresponding to: i) $\mathrm{N}$ doses $\left(0,120,180\right.$, and $240 \mathrm{~g} \mathrm{~N}$ hole $\left.^{-1}\right)$, ii) $\mathrm{K}$ doses $\left(0,120,180\right.$, and $240 \mathrm{~g} \mathrm{~K}_{2} \mathrm{O}$ hole $\left.^{-1}\right)$, and iii) renewing the water maintenance in vase (with and without renewal) with three replicates of three stems each. Some evaluations were observed during the Study, such as: the water uptake by the flower stems; loss of fresh weight of the flower stems, dry weight of the flower stems and post-harvest longevity. The dose of $180 \mathrm{~g}_{\text {hole }}^{-1}$ both as $\mathrm{N}$ and $\mathrm{K}$ provided the longevity of the flower stems with quality maintenance. The absorption of water by the flower stems and its dry mass after harvesting are influenced by previous fertilizer $\mathrm{N}$ and $\mathrm{K}$. The renewal of the water maintenance also positively influence the longevity of flower stems and its a management indicated to maintain quality post-harvest.
\end{abstract}

Keywords: Heliconia psittacorum. Post-harvest quality. Maintenance solution.

\footnotetext{
*Autor correspondente

${ }^{1}$ Recebido para publicação em 01/05/2014; aceito em 27/04/2015.

Parte do Trabalho de Conclusão de Curso da primeira autora.

${ }^{2}$ Mestrado em Ciências Florestais, Universidade de Brasília (UNB), Brasília (DF); genildacanuto@gmail.com

${ }^{3}$ Colegiado de Engenharia Agronômica, UNIVASF, Petrolina (PE); markilla.beckmann@univasf.edu.br.

${ }^{4}$ Mestrado em Agronomia-Fitotecnia, Campus Profa. Cinobelina Elvas, UFPI, Bom Jesus (PI); leonardobrito@ufpi.edu.br, marlucelimabj@hotmail.com.

${ }^{5}$ Colegiado de Química, UFPI, Teresina (PI); josy_osajima@yahoo.com.br.
} 


\section{INTRODUÇÃO}

As flores tropicais apresentam duas características fundamentais para ter uma comercialização bem sucedida, quais sejam, beleza e durabilidade pós -colheita. Grande parte das espécies ornamentais tropicais é nativa do Brasil, a qual possui condições de clima e solo favoráveis à produção em larga escala e de excelente qualidade (LIMA; FERRAZ, 2008).

O Nordeste apresenta condições edafoclimáticas adequadas para se cultivar uma grande variedade de espécies tropicais as quais pertencem principalmente a seis famílias distintas (Strelitziaceae, Heliconiaceae, Costaceae, Zingiberaceae, Cannaceae e Araceae), garantindo a regularidade de oferta de helicônia, alpínia, antúrio, tapeinochilos, bastão do imperador e outras folhagens tropicais cada vez mais concorridas no mercado internacional (LOGES et al., 2005).

Para Mattiuz et al. (2005), Bayogan, Jaroenkit e Paull (2008), Santos, Santoz e Lima (2008), Pietro, Mattiuz e Mattiuz (2010) e Spricigo et al. (2010) a longevidade de flores cortadas é extremamente importante e o uso de soluções conservantes pode contribuir para manter a qualidade e prolongar a durabilidade pós-colheita. No entanto, segundo Nowak e Rudnicki (1990), a longevidade também é determinada por vários fatores de pré e pós-colheita e, além disso, está relacionada com diferenças genéticas, fisiológicas e anatômicas entre espécies e cultivares que conferem características próprias a cada produto, de forma que os sintomas de senescência e a máxima vida de vaso podem variar muito.

De acordo com Pellegrini e Bellé (2008), a qualidade nutricional das plantas é fundamental, pois influencia diretamente na conservação das flores, ou seja, uma adubação inadequada pode acarretar deficiências nutricionais e afetar a qualidade do produto comercial, sendo uma consequência da redução de fotoassimilados, principalmente carboidratos, que segundo Nowak e Rudnicki (1990) quanto maior a sua concentração maior a durabilidade pós-colheita.

Conforme Castro et al. (2007), características importantes para pós-colheita e comercialização de Heliconia psittacorum x H. spathocircinata cv. Golden Torch, como comprimento e diâmetro da haste, comprimento da inflorescência, durabilidade póscolheita e teor de carboidratos das hastes florais são comprometidas quando ocorre deficiência de nitrogênio e potássio. Viégas et al. (2014) também relataram que o nitrogênio foi um dos nutrientes mais limitantes para o crescimento de plantas de cv. Golden Torch. Também para o grupo das plantas tropicais, Viégas et al. (2011) verificaram que o potássio foi um dos nutrientes que manifestou primeiramente os sintomas de deficiência em alpínias, seguido de cálcio e nitrogênio.

Nesse contexto, sugere-se que doses de nitrogênio e de potássio quando associadas na adubação proporcionam uma melhor qualidade das hastes flo- rais de helicônias e consequentemente uma maior longevidade. Enfatiza-se, ainda, as informações acerca da adubação e sua relação com a qualidade póscolheita de hastes florais, especialmente em plantas tropicais que ainda são escassas na literatura científica. Dessa forma, o presente trabalho objetivou avaliar a conservação de inflorescências de helicônias com ou sem renovação da água de manutenção, previamente adubadas com doses crescentes de nitrogênio e potássio nas condições de Bom Jesus (PI).

\section{MATERIAL E MÉTODOS}

O experimento foi desenvolvido no período de 29 de maio de 2011 a 30 de julho de 2012 no Campus Professora Cinobelina Elvas (CPCE) da Universidade Federal do Piauí (UFPI), situado em Bom Jesus, Estado do Piauí, localizado nas coordenadas geográficas $09^{\circ} 04^{\prime} 45^{\prime \prime} \mathrm{S}$ e $44^{0} 18^{\prime} 46^{\prime \prime} \mathrm{W}$ e $322 \mathrm{~m}$ de altitude, pertencente a região sul piauiense com clima quente e úmido, classificado por Köppen como Cwa.

Inicialmente, foram produzidas mudas de helicônias da espécie $H$. psittacorum $x H$. spathocircinata cv. Golden Torch a partir de rizomas coletados em banco ativo de germoplasma do Setor de Horticultura do CPCE/UFPI. Anteriormente ao plantio, fora realizado a padronização e limpeza dos rizomas e, em seguida, a imersão em solução com água sanitária a 5\% por um período de 15 minutos para assepsia. Posteriormente, foram acondicionadas em sacos plásticos com volume de $2 \mathrm{~L}$ preenchidos com substrato composto por areia + esterco bovino na proporção de 2:1 (v/v) dispostos a meia sombra e irrigados uma vez ao dia, baseado em BeckmannCavalcante et al. (2011). Ao completar 60 dias (29 de julho de 2011) as mudas foram transplantadas para o local definitivo, no campo experimental de Floricultura conduzidas a pleno sol.

As mudas foram plantadas individualmente em covas com dimensões de duas vezes o diâmetro do rizoma, abertas em um espaçamento de plantio em fileiras simples com 2,0 m entre rizomas e 3,0 m entre linhas, com densidade de 1666 plantas ha ${ }^{-1}$, conforme recomendações de Lamas (2002). O sistema de irrigação utilizado foi do tipo microaspersão, com microaspersor multifuncional de alcance normal (MFN) Amanco ${ }^{\circledR}$, com uma linha de emissores a cada duas linhas de plantio, 11 emissores em cada linha, distanciados de $6 \mathrm{~m}$, vazão média de $43 \mathrm{~L} \mathrm{~h}^{-1} \mathrm{e}$ raio molhado de $6,2 \mathrm{~m}$. As irrigações foram efetuadas sempre pela manhã, com um tempo médio diário de irrigação de 40 minutos.

A adubação do solo em cobertura foi efetuada com nitrogênio (Uréia, $45 \%$ de $\mathrm{N}$ ), fósforo (Superfosfato Simples, $18 \% \quad \mathrm{P}_{2} \mathrm{O}_{5}$ ) e potássio (Cloreto de Potássio, 58\% de $\mathrm{K}_{2} \mathrm{O}$ ). A quantidade de fósforo aplicada foi de $45 \mathrm{~g} \mathrm{cova}^{-1}$, fornecido em quantidade total, em mistura com o solo da cova de 
plantio. As doses de $\mathrm{N}(0,120,180$ e $240 \mathrm{~g}$ de $\mathrm{N}$ cova $\left.^{-1}\right)$ e $\mathrm{K}\left(0,120,180\right.$ e $240 \mathrm{~g} \mathrm{de}_{2} \mathrm{O}$ cova $\left.^{-1}\right)$ foram divididas em três aplicações iguais, aos três, seis e nove meses após o plantio das mudas no campo, baseado em Oliveira et al. (2006).

$\mathrm{O}$ experimento foi instalado em esquema fatorial $4 \times 4 \times 2$ correspondentes a: i) doses de $\mathrm{N}(0$, 120,180 e $\left.240 \mathrm{~g}_{\text {de }} \mathrm{N}_{\text {cova }}{ }^{-1}\right)$; ii) doses de $\mathrm{K}(0,120$,

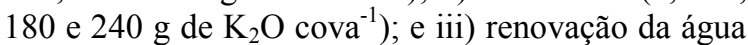
de manutenção (sem e com renovação). Os tratamentos foram distribuídos em blocos casualizados com três repetições e três hastes florais (inflorescências) cada uma. Para isto, foi realizada a colheita das inflorescências no início da manhã para evitar exposição ao calor excessivo após o corte, ocasionando desidratação das hastes (LOGES et al., 2005). Após a colheita, as hastes foram imediatamente conduzidas ao laboratório de Análise de Crescimento Vegetal, onde foram padronizadas, descartando-se as danificadas ou as que não apresentaram o ponto de colheita especificado com no mínimo de duas brácteas abertas (LAMAS, 2002). O comprimento das hastes foi uniformizado para $35 \mathrm{~cm}$, sem considerar as inflorescências, cortando-as em bisel.

Posteriormente, as hastes foram etiquetadas, pesadas e distribuídas ao acaso em recipientes, contendo $500 \mathrm{~mL}$ de água destilada como fonte para a manutenção (condicionamento) das hastes em vaso, e vedados com filme de PVC ao redor da haste para evitar a evaporação da água. Para o uso da água destilada foram realizados os seguintes tratamentos de renovação: 1) água destilada, sem renovação (a quantidade de água foi mensurada a cada dois dias, não renovada e completada quando necessário para atingir a marca dos $500 \mathrm{~mL}$ ); e 2) água destilada, com renovação (a água foi mensurada, descartada e renovada a cada dois dias).

As hastes foram mantidas em sala com temperatura controlada $\mathrm{a} \pm 25^{\circ} \mathrm{C}$, com fonte de luz fornecida parcialmente por tubos de lâmpada fluorescente fria (General Eletric F400 Extralife, $40 \mathrm{~W}$ ) e luz proveniente do ambiente exterior, promovendo luminosidade durante 24 horas. A umidade relativa média da sala foi de aproximadamente $60 \%$.
Para a avaliação da qualidade pós-colheita avaliou-se: 1) Absorção de água pelas hastes florais (AAHF) - determinada a partir da pesagem dos recipientes contendo a água de manutenção, desconsiderando-se as hastes florais; 2) Perda de massa fresca das hastes florais (PMFHF) - as hastes foram pesadas sempre no mesmo horário e mantidas fora da solução pelo menor período de tempo possível (20-40s). Adquiriu-se a massa fresca inicial das inflorescências e a cada dois dias de avaliação foi efetuada nova pesagem. Ao final do experimento, obteve-se a perda de massa fresca das hastes florais; 3) Massa seca das hastes florais (MSHF) - foi determinada utilizando a estufa de secagem a $70^{\circ} \mathrm{C}$ até atingir peso constante, após a avaliação da durabilidade pós-colheita. As variáveis AAHF, PMFHF e MSHF foram baseadas em Durigan et al. (2013); e 4) Longevidade póscolheita (POSC) - foi realizada diariamente até a obtenção da nota 2 (dois). Esta avaliação foi realizada sob o critério de notas adaptado de Castro, May e Gonçalves (2007), em que: nota 0 (zero) - aspecto geral excelente (aspecto de recém-colhido); nota 1 (um) - aspecto geral bom (sinais de senescência pouco característicos, com perda de brilho); e nota 2 (dois) - aspecto geral regular (com início de murcha ou com discreto escurecimento das brácteas).

Os dados foram submetidos a análise de variância pelo teste $\mathrm{F}$ para diagnóstico de efeito significativo e os tratamentos de renovação da água foram comparados entre si pelo teste de Tukey para avaliação de diferença significativa. Foram efetuadas análises quantitativas de regressão múltipla utilizando-se o Software SigmaPlot 10.0.

\section{RESULTADOS E DISCUSSÃO}

Pelos resultados da análise de variância apresentados na Tabela 1 observou-se que as doses de nitrogênio apresentaram significância somente para as variáveis de absorção de água pelas hastes florais (AAHF) e massa seca da haste floral (MSHF). No entanto, não houve ajuste de equação para estas variáveis.

Tabela 1. Absorção de água pelas hastes florais (AAHF), perda de massa fresca das hastes florais (PMFHF), massa seca da haste floral (MSHF) e longevidade pós-colheita (POSC) de Heliconia psittacorum x H. spathocircinata cv. Golden Torch em função das doses de nitrogênio e potássio e renovação da água de manutenção, Bom Jesus (PI), 2012.

\begin{tabular}{|c|c|c|c|c|}
\hline \multirow{2}{*}{ Causa de variação } & AAHF & PMFHF & MSHF & POSC \\
\hline & $-\mathrm{mL}-$ & $-\mathrm{mg}-$ & $-\mathrm{mg}-$ & $-\operatorname{dias}-$ \\
\hline Doses de Nitrogênio (N) ("F") & $5,57 * *$ & $1,13^{\mathrm{ns}}$ & $3,58 *$ & $1,94^{\mathrm{ns}}$ \\
\hline Doses de Potássio (K) (“F”) & $2,06^{\mathrm{ns}}$ & $1,91^{\mathrm{ns}}$ & $7,87 * *$ & $1,85^{\mathrm{ns}}$ \\
\hline Renovação da água (R) (“F”) & $1,06^{\mathrm{ns}}$ & $2,44^{\mathrm{ns}}$ & $0,22^{\mathrm{ns}}$ & $10,56^{* *}$ \\
\hline Com renovação & $0,19 \mathrm{a}$ & $2,97 \mathrm{a}$ & $7,05 \mathrm{a}$ & $10,58 \mathrm{a}$ \\
\hline Sem renovação & $0,19 \mathrm{a}$ & $3,23 \mathrm{a}$ & $6,92 \mathrm{a}$ & $9,50 \mathrm{~b}$ \\
\hline
\end{tabular}

Revista Caatinga, Mossoró, v. 28, n. 3, p. 61 - 67, jul. - set., 2015 
Tabela 1. Continuação.

\begin{tabular}{lcccc}
\hline \multirow{2}{*}{ Causa de variação } & AAHF & PMFHF & MSHF & POSC \\
\cline { 2 - 5 } & $-\mathrm{mL}-$ & $-\mathrm{mg}-$ & $-\mathrm{mg}-$ & - dias - \\
\hline DMS & 0,01 & 0,33 & 0,53 & 0,67 \\
\hline Interação N x K (Valor “F”) & $1,18^{\mathrm{ns}}$ & $1,10^{\mathrm{ns}}$ & $1,03^{\mathrm{ns}}$ & $2,23^{*}$ \\
Interação N x R & $0,89^{\mathrm{ns}}$ & $0,15^{\mathrm{ns}}$ & $0,03^{\mathrm{ns}}$ & $1,02^{\mathrm{ns}}$ \\
Interação K x R & $0,10^{\mathrm{ns}}$ & $0,82^{\mathrm{ns}}$ & $0,23^{\mathrm{ns}}$ & $0,85^{\mathrm{ns}}$ \\
Interação N x K x R & $1,53^{\mathrm{ns}}$ & $1,31^{\mathrm{ns}}$ & $1,35^{\mathrm{ns}}$ & $0,92^{\text {ns }}$ \\
\hline C.V. (\%) (b) & 14,71 & 25,82 & 18,54 & 16,26 \\
\hline
\end{tabular}

DMS = diferença mínima significativa; $\mathrm{C} . \mathrm{V} .=$ coeficiente de variação; $\mathrm{ns}=$ não significativo $(\mathrm{p}>=0,05) ; * *=$ significativo ao nível de $1 \%$ de probabilidade; e $*$ significativo ao nível de $5 \%$ de probabilidade.

As doses crescentes de potássio apresentaram significância apenas para a MSHF (Tabela 1), na qual a maior dose proporcionou o maior valor de massa com 7,72 g (Figura 1). De acordo com Marschner (2005), o potássio, dentre as várias funções nos vegetais, está intimamente ligado à fotossíntese, tem papel importante nas reações enzimáti- cas, atua no metabolismo e transporte dos carboidratos e influencia na manutenção da qualidade dos produtos, sugerindo que ao suprir a planta adequadamente com este nutriente ocorre um aumento na síntese de carboidratos em razão da maior taxa fotossintética, bem como a eficiência de translocação desses compostos.

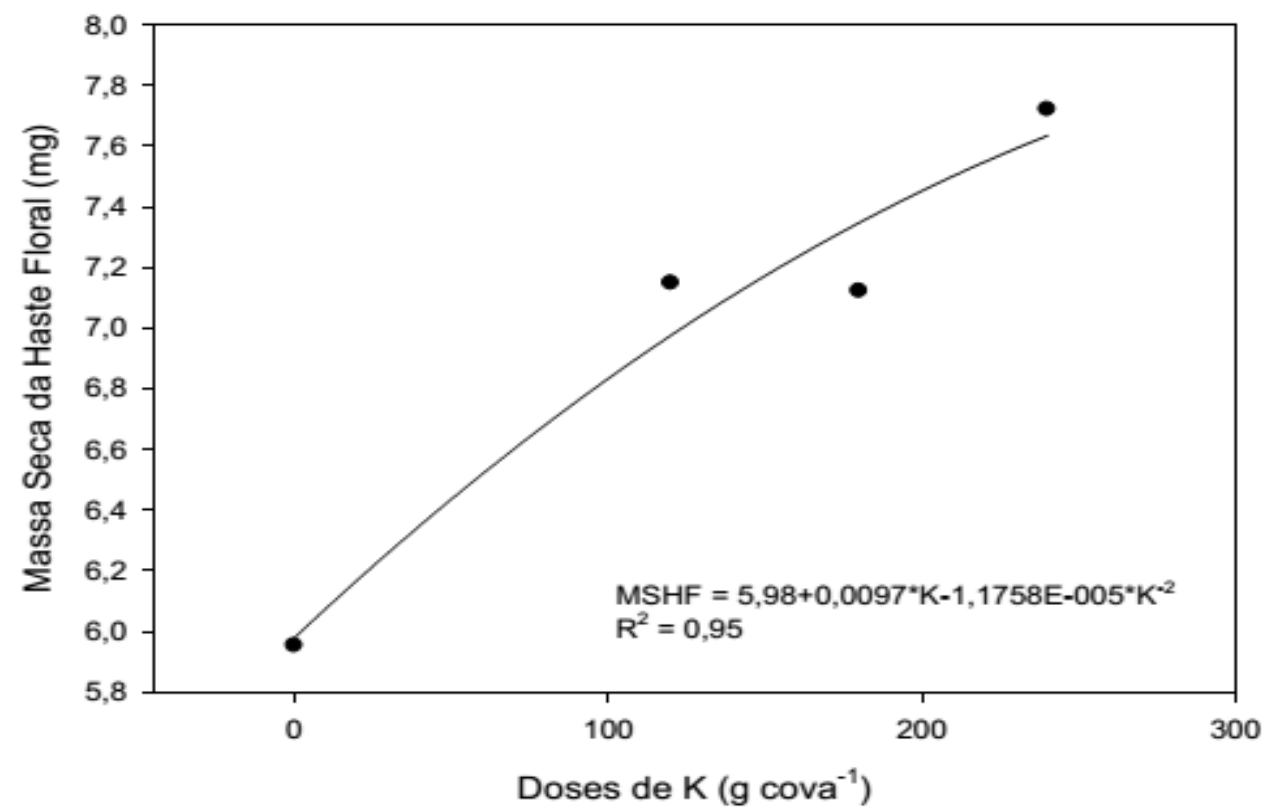

Figura 1. Massa seca da haste floral (MSHF) de plantas de Heliconia psittacorum x H. spathocircinata cv. Golden Torch em função de doses de potássio, Bom Jesus (PI), 2012.

Castro et al. (2007) observaram que a deficiência de K em helicônia cv. Golden Torch resultou em menor massa de matéria seca da haste floral, diminuição da durabilidade pós-colheita, paralelamente ao acúmulo de carboidratos nas folhas, concluíndo que hastes florais com maior massa de matéria seca apresentam maior durabilidade pós-colheita.

Adicionalmente, Hermans et al. (2006) relataram que sob deficiência de $\mathrm{K}$ as plantas acumulam mais carboidratos nas folhas, associando com a restrição do transporte da sacarose, redução da produção de matéria seca e alteração no padrão de partição de fotoassimilados entre os tecidos da planta.

Em trabalho realizado com Heliconia caribeae, Yee e Tissue (2005) observaram que os teores de carboidratos variam entre as brácteas e outras partes da planta, na fase de florescimento, sugerindo que o acúmulo de amido no pecíolo, rizoma e brácteas não é utilizado para a produção da flor, mas é acumulado para potencial uso na produção de frutos. Partindo desse princípio, como os frutos estão localizados nas brácteas que compõem as hastes e estas são utilizadas como flor de corte, quanto maior esse acúmulo de reservas maior a durabilidade 
pós-colheita.

O tratamento com renovação apresentou superioridade estatística em relação a não renovação da água de manutenção para a variável longevidade pós -colheita POSC, ou seja, atingiram a primeira vez a nota 2 (início do murchamento e/ou discreto escurecimento das brácteas), em média 10,58 dias após a colheita (Tabela 1). Este resultado se apresentou superior ao encontrado na literatura, no qual Ribeiro et al. (2010) ao avaliarem hastes de Heliconia rauliana submetidas a diferentes soluções de manutenção obtiveram para o tratamento controle (somente água destilada, sem renovação) uma longevidade de apenas 8 dias. Por outro lado, Salanon, Ketsa e Van Doorn (2003), trabalhando com inflorescências de orquídea Dendrobium cv. Jew Yuay Tew observaram aumento na vida de vaso quando mantidas em água esterilizada, pois quando fizeram uso da água não esterelizada ocorreu a presença de bactérias, o que afetou a longevidade das flores.

Embora não tenha sido objeto de estudo, observou-se no decorrer do experimento que o tratamento sem renovação de água se apresentou túrbida e com mau cheiro, o que pode ser um indicativo de proliferação de bactérias ou presença de mucilagem. Segundo Guimarães et al. (2010), as substâncias depositadas na superfície do corte, a exemplo das mucilagens, podem ocasionar obstrução, impedindo a absorção de água, o que pode levar à senescência das flores. Van Dorn, Sinz e Tomassen (2004) obser- varam sintomas de senescências em haste florais de Iris quando constataram a presença de mucilagem na solução de vaso. Dias-Tagliacozzo e Castro (2005) também relataram que hastes florais de orquídeas Phalaenopis e Heliconia psittacorum possuem dificuldades de manutenção de turgescência, especialmente por apresentar exsudação de mucilagem no local da superfície do corte que reduz a absorção de água pela haste. Nesse sentido, percebe-se que a troca da água evita que ocorra acúmulo destes materiais em torno da corte das hastes.

$\mathrm{Na}$ Tabela 1 observou-se o efeito significativo da interação das diferentes doses de $\mathrm{N}$ e $\mathrm{K}$ para a variável POSC. Como consequência, constata-se na Figura 2 que a dose de $180 \mathrm{~g} \mathrm{cova}^{-1} \mathrm{de} \mathrm{N}$ e K promoveu o maior número médio de dias (10,15 dias) em que as hastes mantiveram sua qualidade pós-colheita, resultado que, segundo Marschner (2005), pode ser explicado pela maior eficiência de utilização do $\mathrm{N}$ na presença de $\mathrm{K}$ devido ao envolvimento do $\mathrm{K}$ no transporte de $\mathrm{N}$ para a síntese proteica. Dessa forma, provavelmente o efeito positivo nessa variável se deve ao aumento da produção de carboidratos, permitindo maior absorção de água e, consequentemente, mantendo as hastes com maior durabilidade após a colheita. Nesse sentido, quando as reservas se esgotam a absorção de água pela inflorescência diminui (Walton et al., 2010), o que pode levar à senescência da haste floral.

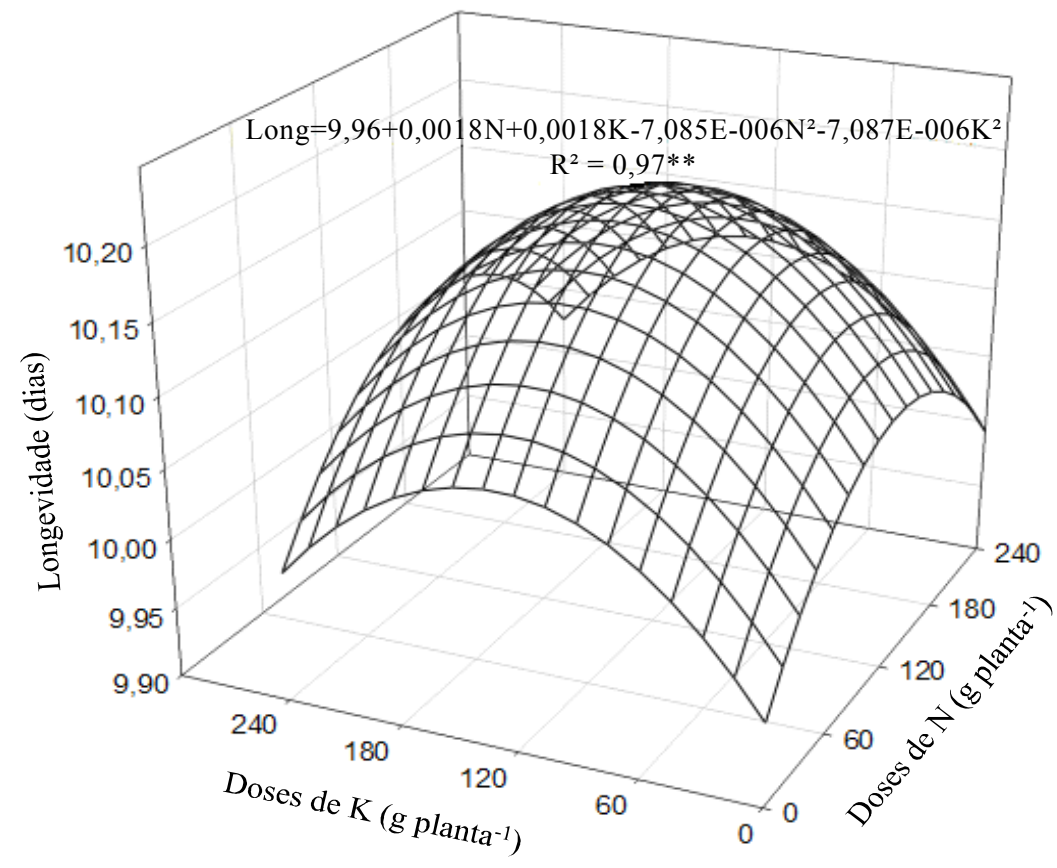

Figura 2. Longevidade pós-colheita de inflorescência Heliconia psittacorum x H. spathocircinata cv. Golden Torch em função de doses de nitrogênio de potássio. Bom Jesus (PI), 2012.

Estudos com plantas ornamentais relacionadas à qualidade e longevidade das hastes florais, ao exemplo de Castro et al. (2007), mostraram que características importantes para pós-colheita e comerci- alização de helicônia cv. Golden Torch, como a durabilidade pós-colheita e teor de carboidratos das hastes florais, são comprometidas quando ocorre deficiência de N, P e K, evidenciando que a qualida- 
de pode ser melhorada por meio da adequada adubação com estes nutrientes. Essas informações corroboram com Sonego e Brackmann (1995) ao relatarem que a longevidade das inflorescências é proporcional ao aumento das doses de $\mathrm{N}$ e $\mathrm{K}$ em virtude das reservas nutricionais adquiridas pela planta até o momento da colheita. Em estudo recente com Ranunculus asiaticus, uma planta ornamental, Bernstein et al. (2011) também verificaram o efeito positivo da adubação nitrogenada e potássica sobre a produção e vida de vaso desta espécie.

De acordo com Marschner (2005), a interação entre nitrogênio e potássio segue a Lei do Mínimo, pois quando o $\mathrm{N}$ é aplicado em quantidade suficiente para haver elevação da produção esta passa a ser limitada pelos baixos teores de $\mathrm{K}$ aplicados ao solo. Viana e Kiehl (2010) também relatam que a disponibilidade do nitrogênio e do potássio e a adequada proporção entre eles no solo são fatores importantes nos processos de crescimento e desenvolvimento das plantas. Os autores Xu, Wolf e Kafkafi (2002) informaram que o metabolismo de nitrogênio nas plantas requer adequadas quantidades de potássio no citoplasma, sendo importante para a produção de aminoácidos e produtividade das culturas.

\section{CONCLUSÕES}

Nas condições de cultivo adotadas, para manutenção da qualidade das inflorescências de helicônia cv. Golden Torch a dose de $180 \mathrm{~g} \mathrm{cova}^{-1}$ de $\mathrm{N}$ e $\mathrm{K}$ proporciona a maior longevidade.

A absorção de água pelas hastes florais e massa seca da haste floral após a sua colheita são influenciadas pela adubação prévia de $\mathrm{N}$ e $\mathrm{K}$.

Entre práticas de manejo adotadas para conservação de inflorescências de helicônia cv. Golden Torch a renovação da água de manutenção é a mais indicada.

\section{AGRADECIMENTOS}

À Fundação de Amparo à Pesquisa do Estado do Piauí (FAPEPI) pelo apoio financeiro ao projeto executado e à Fazenda Mumbecas em nome de Maria do Carmo pela doação das mudas de helicônias que proporcionaram as inflorescências para o desenvolvimento deste trabalho.

\section{REFERÊNCIAS}

BAYOGAN, E. R. V.; JAROENKIT, T.; PAULL, R. E. Postharvest life of Bird-of-Paradise inflorescences. Postharvest Biology and Technology, Amsterdam, v. 48, n. 2, p. 259-263, 2008.
BECKMANN-CAVALCANTE, M. Z. et al. Alternative substrates for production of Heliconia psittacorum L. seedlings under shade and open field conditions. African Journal of Biotechnology, Johannesburg, v. 10, n. 68, p. 15272-15277, 2011.

BERNSTEIN, N. et al. Effects of K and N Nutrition on Function and Production of Ranunculus asiaticus. Pedosphere, Amsterdam, v. 21, n. 3, p. 288-301, 2011.

CASTRO, A. C. R. et al. Hastes florais de Heliconia sob deficiência de macronutrientes. Pesquisa Agropecuária Brasileira, Brasília, v. 42, n. 9, p. 1299 1306, 2007.

CASTRO, C. E. F.; MAY, A.; GONÇALVES, C. Espécies de helicônia como flores de corte. Revista Brasileira de Horticultura Ornamental, Campinas, v. 12, n. 2, p. 87-96, 2007.

DIAS-TAGLiACOSO, G. M.; CASTRO, C. E. F. Manutenção da qualidade pós-colheita de Zingibers pectabile Griff. Horticultura Brasileira, Brasília, v. 23 , n. 2 , p. 563,2005

DURIGAN, M. F. B. et al. Uso de soluções de manutenção contendo ácido cítrico, cloro ou 8-HQC na conservação pós-colheita de flores cortadas de gérbera Suzanne. Revista Brasileira de Horticultura Ornamental, Campinas, v. 18, p. 107-116, 2013.

GUIMARÃES, A. A. et al. Fisiologia pós-colheita de Heliconia spp. Revista Verde, Mossoró, v. 5, n. 5. p. 38-49, 2010.

HERMANS, C. et al. How do plants respond to nutrient shortage by biomass allocation? Trends in Plant Science, Amsterdam, v. 11, n. 12, p. 610-617, 2006.

LAMAS, A. M. Floricultura tropical: técnicas de cultivo e pós-colheita de flores e folhagens. 1. ed. Fortaleza, CE: Instituto Frutal, 2002, 135 p.

LIMA, J. D.; FERRAZ, M. V. Cuidados na colheita e na pós-colheita das flores tropicais. Revista Brasileira de Horticultura Ornamental, Campinas, v. 14 , n. 1, p. 29-34, 2008

LOGES, V. et al. Colheita, pós-colheita e embalagem de flores tropicais em Pernambuco. Horticultura Brasileira, Brasília, v. 23, n. 3, p. 699-702, 2005.

MARSCHNER, H. Mineral nutrition of higher plants. 6. ed. London: Academic Press, 2005. 889 p.

MATTIUZ, C. F. M. et al. Efeito de agentes químicos na conservação pós-colheita de inflorescências de Alpinia purpurata (Vieill) K. Schum. Revista 
Brasileira de Horticultura Ornamental, Campinas, v. 11, n. 1, p. 1, p. 35-42, 2005.

NOWAK, J.; RUDNICKI, R. M. Postharvest handling and storage of cut flowers, florist greens, and potted plants. Portland: Timber Press, 1990. $210 \mathrm{p}$.

OLIVEIRA, R. F. et al. Produção de flores de Heliconia bihai com adubação mineral e orgânica. Belém, PA: Embrapa Amazônia Oriental, 2006. 5 p. (Circular Técnica 166).

PELLEGRINI, M. B. Q.; BELLÉ, R. A. O que você precisa saber sobre pós-colheita de flores. Revista Campos \& Negócios, Uberlândia, v. 5, n. 69, p. 4142, 2008 .

PIETRO J.; MATTIUZ, B.; MATTIUZ C. F. M.; Influência do 1-mcp na conservação pós-colheita de rosas cv. Vega. Ciência e Agrotecnologia, Lavras, v. 34 , n. 5 , p. 1176-1183, 2010.

RIBEIRO, W. S. et al. Pós-colheita e conservação de inflorescências de Heliconia marginata x heliconia bihai (Heliconia rauliana) submetidas a soluções de manutenção. Agropecuária Técnica, Areia, v. 31, n. 1, p. 70-74, 2010 .

SALANON, C. R.; KETSA, S.; VAN DOORN, W. G. Effect of aminooxyacetic acid and sugars on the vase life of Dendrobium flowers. Postharvest Biology and Technology, Amsterdam, v. 29, n. 1, p. 93100, 2003.

SANTOS, M. H. L. C.; SANTOZ, E. E. F.; LIMA, G. P. P. Soluções conservantes em sorvetão póscolheita. Ciência Rural, Santa Maria, v. 38, n. 8, p. 2354-2357, 2008.

SONEGO, B; BRACKMANN, A. Conservação póscolheita de flores. Ciência Rural, Santa Maria, v. 25, n. 3, p. 473-479, 1995.

SPRICIGO P. C. et al. Soluções de manutenção na pós-colheita de Chrysanthemum morifolium cv. Dragon Chrysanthemum morifolium cv. Dragon postharvest maintenance solutions. Ciência e Agrotecnologia, Lavras, v. 34, n. 5, p. 1238-1244, 2010.

VAN DOORN, W. G.; SINZ, A.; TOMASSEN, M. M. Daffodil flowers delay senescence in cut Iris flowers. Phytochemistry, Amsterdam, v. 65, n. 5, p. 571-577, 2004.

VIANA, E. M.; KIEHL, J. C. Interação de nitrogênio e potássio na nutrição, no teor de clorofila e na atividade da redutase do nitrato em plantas de trigo. Bragantia, Campinas, v. 69, n. 4, p. 975-982, 2010.
VIÉGAS, I. de J. M. et al. Growth and visual symptoms of macronutrient deficiency and zinc in Heliconia psittacorum cv. Golden Torch. Journal of Food, Agriculture \& Environment, Helsinki, v. 12 , n. 1, p. 169-173, 2014.

VIÉGAS, I. de J. M. et al. Visual symptoms, growth and nutrients of Alpinia purpurata plants exposed to $\mathrm{N}, \mathrm{P}, \mathrm{K}, \mathrm{Ca}, \mathrm{Mg}$ and $\mathrm{S}$ deficiencies. Journal of Food, Agriculture \& Environment, Helsinki, v. 98, n. 3-4, p. 1048-1051, 2011

WALTON, E. F. et al. The dynamics of starch and sugar utilization in cut peony (Paeonia lactiflora Pall.) stems during storage and vase life. Postharvest Biology and Technology, Amsterdam, v. 58, n. 2, p. 142-146, 2010.

XU, G.; WOLF, S.; KAFKAFI, U. Ammonium on potassium interaction in sweet pepper. Journal of Plant Nutrition, Nova York, v. 25, n. 4, p. 719-734, 2002.

YEE, D.; TISSUE, D.T. Relationships between non structural carbohydrate concentration and flowering in a subtropical herb, Heliconia caribaea (Heliconiaceae). Caribbean Journal of Science, Mayagüez, v. 41, n. 2, p. 243-249, 2005. 